\title{
Novel Insight of Cytokeratin 14 as a Biomarker in Diagnosing Bladder Cancer
}

\author{
Taufiq Nur Budaya ${ }^{1 *}$, Happy Kurnia Permatasari ${ }^{2}$, Widodo Widodo ${ }^{3}$, Sumarno Reto Prawiro ${ }^{4}$ \\ ${ }^{1}$ Department of Urology, Faculty of Medicine, Universitas Brawijaya, Dr Saiful Anwar General Hospital, Malang, Indonesia; \\ ${ }^{2}$ Department of Biomedical Science, Faculty of Medicine, Universitas Brawijaya, Malang, Indonesia; ${ }^{3}$ Department of Biology, \\ Faculty of Mathematics and Natural Science, Universitas Brawijaya, Malang, Indonesia; ${ }^{4}$ Department Clinical Microbiology, \\ Faculty of Medicine, Universitas Brawijaya, Dr Saiful Anwar General Hospital, Malang, Indonesia
}

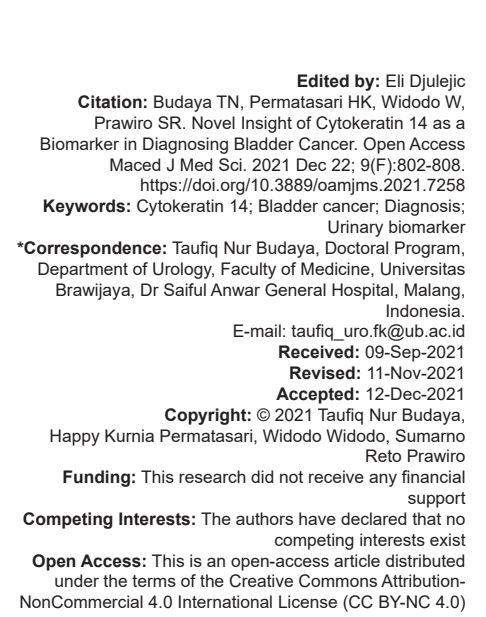

\section{Abstract}

Bladder cancer is the ninth most common type of cancer occurring in men. Screening for bladder cancer is often difficult due to limited proper modality and symptoms that is mild and unspecific. Leaving it untreated leads to greater morbidity and mortality. Therefore, finding a simple biomarker for screening purpose is necessary. Cytokeratin (CK) has been studied extensively as cancer biomarker. Detectable soluble CK was found in body fluid, including urine, and histological specimen using immunoassays. The level of its expression is mainly affected by cell proliferation, apoptosis, and cellular stress. CK 14, which is type I CK, was detected in the basal layer of epithelial cells and specific for squamous type of epithelial cell. CK 14 analysis in bladder cancer has revealed numerous functions such as predicting the development of bladder cancer, differentiating cancer origins, stratifying bladder cancer patients based on disease severity, and predicting bladder cancer recurrence. Its potential to become excellent biomarker makes it subject of interest in research development.

\section{Introduction}

Novel diagnostic modalities to detect bladder malignancies are developing these past years. Up to this moment, the gold standard to diagnose bladder cancer is by cystoscopy assessment. However, this procedure tends to be avoided because of the invasive nature of the cancer. Therefore, patients often feel inconvenient undergoing the procedure [1]. Diagnosing bladder cancer is even more difficult as patients may not exhibit severe symptoms. Typically, it only manifests as painless hematuria which is not specific bladder malignancy [2], [3], [4]. Urinary biomarkers offer promising method to screen for bladder cancer. These biomarkers constitute various substances detected in the course of urine flow. Cytokeratin (CK) has been studied extensively in cases of malignancies. These proteins make up a class of intermediate filaments which contribute in the formation of epithelial cells cytoskeletons. Previously, CKs are believed to represent the occurrence of cell proliferation, apoptosis, or necrosis [5]. Among the 20 types of CKs, CK 14 is a marker of squamous epithelial cells differentiation [6], [7]. Many studies have analyzed CK 14 as diagnostic or prognostic marker in various cancers. CK expression can be detected by immunoassay method. CK is potential urine biomarker to detect bladder cancers. This review aims to discuss the potential role of CK 14 in the diagnosis of bladder cancers.

\section{Burdens of Bladder Cancer}

Bladder cancer is the ninth most common type of all cancers. Male gender is more susceptible to this cancer, as it is ranked the seventh most common type of cancer in males [8]. In 2012, over 430,000 new patients are diagnosed with bladder cancers and 165,000 bladder cancer-related mortalities were reported. The incidence is higher in industrialized countries such as the United States (US) and European countries [9]. From American Cancer Society, 17,240 patients died from bladder cancer. In Indonesia, the exact number of cases is not 
known. GLOBOCAN statistics estimated that there were 5.8 cases in every 100,000 Indonesians [10]. However, the unreported case was not taken into account in this statistics. In general, prevalence and incidence of bladder cancer in each country depend on risk factors. The risk factors include genetic predisposition, age, smoking habit, occupational factors (e.g., exposure to benzidine), diet (e.g., coffee and chocolate), pollution, geographic location (e.g., endemicity of Schistosoma haematobium), and gender (male predominance) [11]. Bladder cancer is divided into two major subtypes based on the type of cell involved: Urothelial bladder cancer (UBC) and non-UBC (NUBC). UBC are most prevalent, occurs in over $90 \%$ of all bladder cancer cases, with the remaining cases are NUBC. NUBC types are squamous cell carcinoma (SCC), adenocarcinoma, and small cell carcinoma (SmCC), also known as neuroendocrine tumor [12]. NUBC poses substantially lower value of disease-specific survival rate compared to UBC [13].

Aside from the risk of mortality, bladder cancer also impairs activities of daily living, both physically and mentally, leading to increased morbidity. This phenomenon is more dominant in elderly patients. Most common psychological issues observed after the diagnosis of bladder cancer are anxiety and depression. Moreover, these patients also tend to be not active in social life. In some cases, patients may become suicidal, although it is considerably rare. Limitations in daily activities include taking shower, going to toilet, moving a chair, dressing, eating, and walking. Obviously, these problems are more prevalent in patients with cancers of higher staging classification. Females are more prone to suffer from these problems. In addition, female patients are reported to have poorer outcome in the first 2 years following the diagnosis [14]. These detrimental conditions may potentially hinder patients from actively controlling and managing the cancer [15]. Thus, it will lead to worsened morbidity and increased mortality.

\section{Diagnostic Problems of Bladder Cancer}

Ideally, bladder cancer is diagnosed using cytology assessment and histopathological analysis of bladder biopsy as the gold standard [16]. However, it can be troublesome especially in remote areas due to limited facilities. Therefore, this condition may significantly delay bladder cancer diagnosis and negligence of disease severity. This phenomenon is still observed in Indonesia. Many health centers far away from metropolitan cities lack of health facilities, from diagnostic to treatment modalities. This results in the increasing number of severe cases of bladder cancer. A great proportion of patients are presented with locally advanced or advanced bladder cancer at the time of diagnosis [17]. These patients may have suffered from bladder cancer for up to 5 years. Plus, each patient's level of knowledge also plays an important role in the diagnosis. Simple diagnostic kit could become an effective strategy for immediate and appropriate diagnosis even in remote areas, such as urinary biomarker. As a marker of epithelial differentiation, diagnostic kits based on CKs could be developed.

\section{CK 14}

CKs are a class of intermediate filaments which form the cytoskeletal networks of the cells. Cytoskeleton itself helps maintain the structural integrity of the cell upon the presence of mechanical stress and aids in cell movement and division [18], [19]. There are two types of CKs, acidic CKs (40-56 kDa), well known as the type I intermediate filament, consisting of CK9-CK20, and basic CKs (53-68 kDa), well known as the type II intermediate filament, which consist of CK1-8. This classification is based on the molecular weight and isoelective $\mathrm{pH}$ of each CK. Type I CK is of low molecular weight, whereas type II CK has higher molecular weight. CKss with lower molecular weight are observed in non-stratified epithelial cells, and vice versa [20]. Apart from CKs, intermediate filaments are also classified into type III (desmin, glial fibrillary protein/ GFAP, peripherin, and vimentin), type IV (neurofilament proteins and internexin), and type $\mathrm{V}$ (lamins, exclusive to the cell nuclei) intermediate filaments. In addition, filensin and phakinin are currently included in the type VI intermediate filaments [21]. All CKs are encoded by 2 large families of genes consisting of nearly 50 distinct genes [5]. Similar to all intermediate filaments, the characteristic structures of the CKs lie on the three domains namely the non-helical $\mathrm{N}$-terminal segment, the non-helical $\mathrm{C}$-terminal segment, and the helical central rod [21].

During the apoptosis of epithelial cells, reorganization of the cell cytoskeletons occurs. This process therefore also reorganizes the CKs into granular structures. The enzyme caspases are needed to aid the cleavage of the CKs. The cleavage of the CK14 occurs at the sequence VEMD/A which is also identified in the CK12 to CK17. In contrast to this site, CK18 and CK19 are cleaved by the caspase at the sequence VEVD/A of the non-helical sequences. In addition, modifications, including glycosylations, transglutaminations, and phosphorylations, of the $\mathrm{N}$-terminal and $\mathrm{C}$-terminal segments may also affect the nature of the CKs. These processes result in the increased solubility of the CKs as they will be present as degraded protein fragments of lower molecular weight [5], [21].

CKs are expressed on epithelial cells which are dispersed throughout the body. Each CK is expressed in normal epithelial tissues as well as cancers derived from 
the tissues [22]. Its expression varies depending on the type of the tissue and the development of each tissue itself. Among all CKs, the CK18 and CK19 are the most abundant CKs in the body and malignancies 5 CK 14 is a member of type I CK identified in the basal layer of the epithelial cells and the myoepithelial components of body tissues. Expression of CK14 is tightly associated with the presence of squamous epithelial cells. Previous literatures described CK14 to be expressed in squamous cell differentiation [6], [23], [24].

Mutation of CKs is associated with certain diseases. Along with CK5, CK14 mutation in the basal layer of the epidermis is involved in the epidermolysis bullosa [25]. Whereas abnormalities of CK8 and CK18 are related to hepatic and bowel diseases [26].

\section{Regulation of CK 14}

A few mechanisms in regulating CK14 expression have been proposed although exact pathway remains unclear. Therefore, up to this moment, regulation of cytoskeletal dynamic equilibrium is a field of active research. In general, CK expression is affected by cell proliferation and cellular stress in which each CK has different response. CK 14 is known to be expressed more during cell cycle and on cellular stress such as hypoxia [7]. In the context of cancer, reorganization of CK into stable soluble form of intermediate filament may help cancer cell migration which leads to cancer invasiveness. This process is mediated by actin/CK/14-3-3 $\sigma$ complex and regulated by PKC $\zeta$ [27]. Formation of soluble CK through this process may also yield detectable $\mathrm{CK}$ in the circulation. Another study suggested that CK14 expression is correlated with forkhead box A1 (FOXA1) regulation. In FOXA1-knockout bladder cancer induced mice, CK14 expression increased. Whereas retention of FOXA1 expression was associated with lower CK14 expression. In this study, as CK14 expession increased, urothelial carcinoma became more aggresive and invasive [28]. Ho et al. (2012) linked CK14 expression with Stat3 regulation in bladder cancer model. Stat3-driven bladder cancer was proven to be invasive hence a worse outcome. The cancer was predominantly composed of stem cells characterized by CK14 staining [29]. CK 14 expression was also observed on stem cells differentiating into epidermal component following administration of BMP-4 [30].

\section{Detection of CKs}

CKs might be detected in body fluid such as cyst fluid, cerebrospinal fluid, edema fluid, and urine [21]. Most common methods for analyzing soluble CK fragments (CYFRA) in the serum are tissue polypeptide antigen, tissue polypeptide specific antigen, and CYFRA 21-1. These assays detect the fragmented CKs released by the carcinoma cells as diagnostic or prognostic markers for various types of cancers [31]. Several studies have analyzed CK role in detecting circulating tumor cells using antibody against CK [32], [33], [34]. Antibodies against CKs are most effective in detecting metastatic process of a cancer. Nevertheless, it can also be used to identify cancers containing epithelial components [35]. Whereas in histopathological specimens, their expressions are commonly detected using immunoassays such as immunohistochemistry and immunofluorescence assay. In the context of bladder malignancies, detection of CKs in the urine is the most appropriate screening method. Numerous literatures have reported CK detection as urinary biomarkers for detecting bladder cancers [33], [36], [37], [38]. CK detection with adjunctive modalities such as nuclear matrix protein-22 or bladder tumor antigen may increase the accuracy in diagnosing bladder cancer.

\section{The Role of CK 14 for the Diagnosis of Bladder Cancer}

CKs have been widely used as biomarkers for detecting and classifying malignancies. At present, a number of processes are believed to enable the release of CKs fragments to the circulation system, thus it can be detected in the blood. Those processes include abnormal mitosis, proteolytic degradation, and spillover from the cells which undergo proliferation, apoptosis, or neoplasm. However, the exact mechanism of this phenomenon is yet to be explained. CK 14 is usually expressed in the tumor peripheral parts [39]. In cases of malignancies, CK14 is less analyzed compared to CK8, CK18, CK19, and CK20 [18]. However, its use offers a potential benefit in clinical practices.

\section{CK 14 Role in Bladder Cancer Screening}

As discussed before, the patterns of CK14 expression can be regarded as specific marker for epithelial differentiation. A study that analyzed CK14 expression in patients with spinal cord injuries, found that 7 of 54 patients had CK14 expression of bladder biopsies in either individual or cluster of cells accordant to squamous cell differentiation [6]. Similar finding was reported as CK14 was expressed 
in SCC of the bladder or UBC with squamous cell component [24]. Another study revealed robust CK14 expression in bladder cancer model mice induced by $\mathrm{N}$-butyl-N-(4-hydroxybutyl) nitrosamine (BBN). In healthy mice, CK14 is expressed sporadically, while in BBN-treated mice, its expression is significantly increased [40]. These studies showed that CK14 expression can help predicting and detecting bladder epithelial metaplasia which results in bladder carcinomas, especially SCC of the bladder. Hence, it is potentially beneficial to screen for bladder malignancies.

\section{CK 14 Role in Differentiating Cancer Origins}

Due to its preponderance on particular tissues, CKs may be used to differentiate the origin of a cancer. A group of CKs, namely CK1, CK5, CK10, and CK14 (34ßE12), was proven to exclude the diagnosis of large-cell neuroendocrine carcinomas and detect the basaloid carcinoma (BC) of the lungs. Morphologically, both carcinomas may express similar features, especially in specimens of low quality [41]. Linskey et al. (2013) reported that CK14, along with CK17, was prominently expressed in basal cell carcinoma with squamous metaplasia (BCCm) [23]. This feature differentiated $\mathrm{BCCm}$ with basal SCC. A study analyzing CK expression in the breast cancer showed that CK5/14 is almost exclusively expressed in BRCA1-associated tumors. In contrast, only a few BRCA2-associated cancer displayed CK4/15 expression [42]. In oral carcinogenesis, CK14 expression was observed in hyperkeratosis with epithelial dysplasia, carsinoma in situ (CIS), and SCC [43]. However, it is not expressed in hyperkeratosis without epithelial dysplasia. Another study suggested that CK14 is expressed in cancers with squamous cell component [44]. Thus, CK14 expression may be a good indicator of SCC. In the setting of bladder cancer, CK14 expression in the urine may raise the suspicion of SCC which typically have poorer prognosis. Gaisa et al. (2011) reported consistent result as CK14 expression was most prominent in SCC of the bladder and decreased as squamous cell component decreased [45]. CK 14 can also be expressed in neuroendocrine tumor specimens along with CK1, CK5, and CK10 [46]. Although considerably rare, CK14 expression may give a cue to the presence of SmCC of the bladder as it is commonly mistaken for another type of bladder cancer. These findings may suggest that CK14 expression may be used to differ several types of cancers. Therefore, clinicians could predict survival rate and recommend appropriate treatment of choice for certain cancer patients.

\section{CK 14 Role in Determining Bladder Cancer Grading}

Rapid progressivity to undifferentiated histopathological structure and invasiveness are some traits of malignant tumor. It is essential to identify cancer aggressiveness to plan an appropriate individual treatment. As many as $10-20 \%$ of bladder cancer cases develop to invasive tumor. Muscle invasive bladder cancer owns a high propensity of distant metastasis and is therefore associated with higher mortality [47]. A number of studies analyzed CK14 expression in a certain grade of malignancies. Southern et al. (2001) reported that CK14 expression is prominent in low-grade squamous intraepithelial lesions of the cervix caused by human papilloma virus (HPV) infection, especially in basal and parabasal regions. Whereas, the expression reduced and became absent in intermediate- or high-grade lesions [48]. Epidemiological study revealed that approximately, $35 \%$ of bladder tumor cases were related to HPV infection [49]. In this case, safe sexual practice is a key to avoid bladder malignancy. The result is consistent with studies regarding oral and lung carcinogenesis in which CK14 expressions were decreased as the degree of dysplasia increased [50], [51], [52]. Moreover, Gruver et al. (2012) also reported that invasive urothelial carcinoma demonstrated low expression of CK14 [53].

Contrast to these findings, Nakayama et al. (2011) reported increased expression of CK14 as squamous intraepithelial neoplasia progressed with the greatest expression observed in CIS [54]. Similar results were identified in other studies about invasive salivary adenoid cystic carcinoma and breast cancer [55], [56]. Recent study also reported that urothelial carcinoma with higher CK14 expression was associated with very poor outcomes related to its invasive properties (Volkmer et al., 2012; Reddy et al., 2015; Jangir et al., 2019) [28], [57], [58]. A number of literatures have mentioned CK14 expression in leading cells in the case of collective invasion (Cheung et al., 2013; Cheung and Ewald, 2016; Wu et al., 2019; Nagai et al., 2021) [2], [55], [59], [60]. In general, increased CK14 expression is associated with higher degree of malignancy [39]. This phenomenon may be explained by possible function of CK14. Alam et al. (2011) reported that in CK14 knockdown cells, cell proliferation and cell cycle progression were suppressed. This was possible as CK14 was removed, there were a reduction in phosphatidylinositol 3-kinase/Akt (PI3K/Akt) signaling involved in cell proliferation and increased Notch-1 signaling involved in cell differentiation [61]. CK 14 expression is potentially able to stratify bladder cancer patients based on its grade of metaplasia and detect invasiveness of bladder cancer. However, further study is still needed. 


\section{CK 14 Role in Predicting Bladder Cancer Recurrence}

Recurrence is a common notion in any type of malignancy. This phenomenon may occur especially when cancer cells are not fully eradicated during treatment. Bladder cancer itself has been known to recur in $50 \%$ to $70 \%$ of cases in 5 years of time. As discussed before, higher CK14 expression may suggest higher grading of bladder cancer. Greater CK14 expression also indicated greater recurrence rate of bladder cancer [57]. In addition, high CK20 and low CK5 expression were also proven to a marker of unfavorable recurrence free survival [62].

\section{Conclusion}

CK 14 is a member of acidic CK and is specific to squamous epithelial cell. Its ubiquitous expression in malignancy makes it a potential biomarker in the management of bladder cancer. CK 14 expression is able to predict bladder cancer, differentiate cancer origin, identify bladder cancer severity, and predict bladder cancer recurrence. However, further research is yet to be conducted to understand the full potential of CK14 as a biomarker of bladder cancer.

\section{References}

1. Lee O, Kang H, Yun S. Urine Cytology and Urinary Biomarkers; 2018.

2. Wu J, Li Z, Wang H, et al. Cathepsin B defines leader cells during the collective invasion of salivary adenoid cystic carcinoma. Int J Oncol. 2019;54(4):1233-44. https://doi.org/10.3892/ ijo.2019.4722

PMid:30968153

3. Beukers W, Kandimalla R, van Houwelingen D, Kovacic $H$, Chin JF, Lingsma HF, et al. The use of molecular analyses in voided urine for the assessment of patients with hematuria. PLoS One. 2013;8(10):e77657. https://doi.org/10.1371/journal pone. 0077657 PMid:24143252

4. Shah D, Qiu X, Shah A, Cao D. Posterior nutcracker syndrome with left renal vein duplication: An uncommon cause of hematuria. Int J Surg Case Rep. 2013;4(12):1142-4.

5. Linder S. Cytokeratin markers come of age. Tumor Biol. 2007;28(4):189-95. https://doi.org/10.1159/000107582 PMid: 17717426

6. Vaidyanathan S, McDicken I, Mansour P, Soni BM, Ikin AJ, Singh $G$, et al. Detection of early squamous metaplasia in bladder biopsies of spinal cord injury patients by immunostaining for cytokeratin 14. Spinal Cord. 2003;41(8):432-4. https://doi. org/10.1038/sj.sc.3101464

PMid: 12883540
7. Frohwitter $\mathrm{G}$, Buerger $\mathrm{H}$, Van Diest $\mathrm{P}$, Korsching $\mathrm{E}$, Kleinheinz $\mathrm{J}$, Fillies T. Cytokeratin and protein expression patterns in squamous cell carcinoma of the oral cavity provide evidence for two distinct pathogenetic pathways. Oncol Lett. 2016;12(1):107-13. https:// doi.org/10.3892/ol.2016.4588

PMid:27347109

8. Cumberbatch M, Jubber I, Black P, Esperto F, Figueroa JD, Kamat AM, et al. Epidemiology of bladder cancer: A systematic review and contemporary update of risk factors in 2018. Eur Urol. 2018;74(6):784-95. https://doi.org/10.1016/j. eururo.2018.09.001 PMid:30268659

9. Malats N, Real F. Epidemiology of bladder cancer. Hemato Oncol Clin North Am. 2015;29(2):177-89. PMid:25836927

10. Ferlay J, Shin H, Bray F, Forman D, Mathers C, Parkin D. Estimates of worldwide burden of cancer in 2008: GLOBOCAN 2008. Int J Cancer. 2010;127(12):2893-917. https://doi. org/10.1002/ijc.25516 PMid:21351269

11. Burger M, Catto J, Dalbagni G, Grossman HB, Herr H, Karakiewicz $\mathrm{P}$, et al. Epidemiology and risk factors of urothelial bladder cancer. Eur Urol. 2013;63(2):234-41. https://doi. org/10.1016/j.eururo.2012.07.033

PMid:22877502

12. Ploeg M, Aben K, Hulsbergen-van de Kaa C, Schoenberg M Witjes J, Kiemeney L. Clinical epidemiology of nonurothelial bladder cancer: Analysis of The Netherlands cancer registry. J Urol. 2010;183(3):915-20. https://doi.org/10.1016/j. juro.2009.11.018

PMid:20083267

13. Martin J, Jefferson F, Huang M, Sung JM, Chang J, Piranviseh K et al. A California cancer registry analysis of urothelial and nonurothelial bladder cancer subtypes: Epidemiology, treatment, and survival. Clin Genitourin Cancer. 2020;18(3):e330-6. https:// doi.org/10.1016/j.clgc.2020.01.002

PMid:32144047

14. Richters A, Dickman P, Witjes J, Boormans J, Kiemeney L, Aben K. Bladder cancer survival: Women only fare worse in the first two years after diagnosis. Urol Oncol. 2019;37(12):853-61. https://doi.org/10.1016/j.urolonc.2019.08.001 PMid:31481299

15. Ungerer G, Anwar T, Golzy M, Murray K. Living with bladder cancer: Self-reported changes in patients' functional and overall health status following diagnosis. Eur Urol Open Sci. 2020;20:14-9. https://doi.org/10.1016/j.euros.2020.06.007 PMid:34337455

16. McAninch J, Lue T, Smith D. Smith and Tanagho's Genera Urology. New York: McGraw-Hill Medical; 2013.

17. Abdih M, Djatisoesanto W, Hardjowijoto S. Profile of bladder transitional cell cancer in soetomo hospital Surabaya. Indones $\mathrm{J}$ Urol. 2014;21(2):31.

18. Cho $Y$, Jung S, Hwang E. Novel and emerging surveillance markers for bladder cancer. In: Bladder Cancer. 2018. p. $599-612$

19. Lee $\mathrm{O}$, Kang $\mathrm{H}$, Yun $\mathrm{S}$. Urine cytology and urinary biomarkers In: Bladder Cancer. 2018. p. 67-81.

20. Malik SN, Alam MK. Cytokeratin-14 expression in normal oral mucosal tissue, oral submucous fibrosis and oral squamous cell carcinoma: An immnohistochemical study. Int Med J. 2014;21(2):223-225

21. Barak V, Goike H, Panaretakis K, Einarsson R. Clinical utility of cytokeratins as tumor markers. Clin Biochem. 2004;37(7):529-40. https://doi.org/10.1016/j.clinbiochem.2004.05.009

PMid:15234234 
22. Rahmani A, Babiker A, AlWanian W, Elsiddig S, Faragalla $H$, Aly S. Association of cytokeratin and vimentin protein in the genesis of transitional cell carcinoma of urinary bladder patients. Disease Markers. 2015;2015:204759. https://doi. org/10.1155/2015/204759

PMid:26640315

23. Linskey K, Gimbel D, Zukerberg L, Duncan L, Sadow P Nazarian R. BerEp4, cytokeratin 14, and cytokeratin 17 immunohistochemical staining aid in differentiation of basaloid squamouscellcarcinomafrombasalcellcarcinomawithsquamous metaplasia. Arch Pathol Lab Med. 2013;137(11):1591-8. https:// doi.org/10.5858/arpa.2012-0424-OA

PMid:24168496

24. Hammam $\mathrm{O}$, Wishahi $\mathrm{M}$, Khalil $\mathrm{H}$. Expression of cytokeration $7,20,14$ in urothelial carcinoma and squamous cell carcinoma of the Egyprian urinary bladder cancer. J Egypt Soc Parasitol. 2014;44(3):733-40. PMid:25643514

25. Gleason C, Juul S. Avery's Diseases of the Newborn. Philadelphia, PA: Elsevier; 2018.

26. Laurent G, Shapiro S. Encyclopedia of Respiratory Medicine. Amsterdam: Boston; 2006.

27. Boudreau A, Tanner K, Wang D, Geyer F, Reis-Filho J, Bissell M. 14-3-3 stabilizes a complex of soluble actin and intermediate filament to enable breast tumor invasion. Proc Natl Acad Sci. 2013;110(41):e3937-44. https://doi.org/10.1073/ pnas. 1315022110

PMid:24067649

28. Reddy O, Cates J, Gellert L, Crist HS, Yang Z, Yamashita H, et al. Loss of FOXA1 drives sexually dimorphic changes in urothelial differentiation and is an independent predictor of poor prognosis in bladder cancer. Am J Pathol. 2015;185(5):1385-95. https://doi.org/10.1016/j.ajpath.2015.01.014

PMid:25907831

29. Ho P, Lay E, Jian W, Parra D, Chan K. Stat3 activation in urothelial stem cells leads to direct progression to invasive bladder cancer. Cancer Res. 2012;72(13):3135-42. https://doi. org/10.1158/0008-5472.CAN-11-3195

PMid:22532166

30. Osei-Bempong $\mathrm{C}$, Figueiredo $\mathrm{F}$, Lako $\mathrm{M}$. The limbal epithelium of the eye a review of limbal stem cell biology, disease and treatment. BioEssays. 2013;35(3):211-9. https://doi. org/10.1002/bies.201200086

PMid:23129317

31. Giovanella L, Imperiali M, Trimboli P. Role of serum cytokeratin 19 fragment (Cyfra 21.1) as a prognostic biomarker in patients with differentiated thyroid cancer. Sci Rep. 2017;7(1):7359.

32. Weissenstein U, Schumann A, Reif M, Link S, Toffol-Schmidt U, Heusser P. Detection of circulating tumor cells in blood of metastatic breast cancer patients using a combination of cytokeratin and EpCAM antibodies. BMC Cancer. 2012;12(1):206. https://doi.org/10.1186/1471-2407-12-206 PMid:22646670

33. Li J, Chen L, Zhang X, Zhang $Y$, Liu H, Sun B, et al. Detection of circulating tumor cells in hepatocellular carcinoma using antibodies against asialoglycoprotein receptor, carbamoyl phosphate synthetase 1 and pan-cytokeratin. PLoS One. 2014;9(4):e96185. https://doi.org/10.1371/journal. pone.0096185

PMid:24763545

34. Welinder C, Jansson B, Lindell G, Wenner J. Cytokeratin 20 improves the detection of circulating tumor cells in patients with colorectal cancer. Cancer Lett. 2015;358(1):43-6. https://doi. org/10.1016/j.canlet.2014.12.024

PMid:25528628
35. Perry A, Brat D. Neuropathology patterns and introduction. In: Practical Surgical Neuropathology. Amsterdam, Netherlands: Elsevier; 2010. p. 1-14.

36. Li HX, Li M, Li CL, Ma JH, Wang MR, Rao J, et al. ImmunoCyt and cytokeratin 20 immunocytochemistry as adjunct markers for urine cytologic detection of bladder cancer: A prospective study. Anal Quant Cytol Histol. 2010;32(1):45-52. PMid:20701087

37. Guo X, Long J. Cytokeratin-19 fragment in the diagnosis of bladder carcinoma. Tumor Biology. 2016;37(10):14329-30. https://doi.org/10.1007/s13277-016-5223-7 PMid:27448817

38. Mi Y, Zhao Y, Shi F, Zhang M, Wang C, Liu X. Diagnostic accuracy of urine cytokeratin 20 for bladder cancer: A metaanalysis. Asia Pac J Clin Oncol. 2019;15(2):e11-9. https://doi. org/10.1111/ajco.13024

PMid:29931834

39. Weiquan Z, Xiaogang Z. Cytokeratin 14 and cancer. J Int Oncol. 2015;42(6):436. https://doi.org/10.3760/ CMA.J.ISSN.1673-422X.2015.06.009

40. Li $\mathrm{Y}$, Jia $\mathrm{X}$, Jiang $\mathrm{Y}$, Wang $\mathrm{W}$, Wang $\mathrm{YL}$, Wang $\mathrm{XL}$, et al. Differential expression of cytokeratin 14 and 18 in bladder cancer tumorigenesis. Exp Biol Med. 2018;243(4):344-9. https:// doi.org/10.1177/1535370218754493 PMid:29350066

41. Sturm $N$, Lantuéjoul $S$, Laverrière $M$, Papotti $M$, Brichon $P Y$, Brambilla C, et al. Thyroid transcription factor 1 and cytokeratins $1,5,10,14(34 \beta \mathrm{E} 12)$ expression in basaloid and largecell neuroendocrine carcinomas of the lung. Hum Pathol. 2001;32(9):918-25. https://doi.org/10.1053/hupa.2001.27110 PMid: 11567220

42. Laakso M, Loman N, Borg A, Isola J. Cytokeratin 5/14-positive breast cancer: True basal phenotype confined to BRCA1 tumors. Mod Pathol. 2005;18(10):1321-8. https://doi.org/10.1038/ modpathol.3800456

PMid:15990899

43. Okada $Y$, Moride M. Immunohistochemical study of differential expressions of cytokeratin-13, $-14,-17$ and p53 in epithelial dysplasia and carcinoma of the tongue. J Hard Tissue Biol. 2010;19(2):123-30. https://doi.org/10.2485/ JHTB.19.123

44. Chu P, Lyda M, Weiss L. Cytokeratin 14 expression in epithelial neoplasms: A survey of 435 cases with emphasis on its value in differentiating squamous cell carcinomas from other epithelial tumours. Histopathology. 2001;39(1):9-16.

PMid:11454039

45. Gaisa N, Braunschweig T, Reimer N, Bornemann J, Eltze E, Siegert S, et al. Different immunohistochemical and ultrastructural phenotypes of squamous differentiation in bladder cancer. Virchows Archiv. 2010;458(3):301-12. https:// doi.org/10.1007/s00428-010-1017-2 PMid:21136076

46. Zander D, Farver C. Pulmonary Pathology E-Book. St. Louis: Elsevier; 2016.

47. Ogawa K, Shimizu Y, Uketa S, Utsunomiya N, Kanamaru S. Prognosis of patients with muscle invasive bladder cancer who are intolerable to receive any anti-cancer treatment. Cancer Treat Res Commun. 2020;24:100195. https://doi.org/10.1016/j. ctarc.2020.100195 PMid:32688293

48. Southern S, McDicken I, Herrington C. Loss of cytokeratin 14 expression is related to human papillomavirus type and lesion grade in squamous intraepithelial lesions of the cervix. Hum Pathol. 2001;32(12):1351-5. https://doi.org/10.1053/hupa.2001.29656 PMid: 11774168 
49. Barghi MR, Rahjoo T, Borghei M, Hosseini-Moghaddam SM, Amani D, Farrokhi B. Association between the evidence of human papilloma virus infection in bladder transitional cell carcinoma in men and cervical dysplasia in their spouses. Arch Iran Med. 2012;15(9):572-4

PMid:22924378

50. Chen $\mathrm{Y}$, Cui T, Yang L, Mireskandari M, Knoesel T, Zhang Q, Pacyna-Gengelbach $M$, et al. The diagnostic value of cytokeratin 5/6,14,17, and 18 expression in human non-small cell lung cancer. Oncology. 2011;80(5-6):333-40. https://doi. org/10.1159/000329098

PMid:21791943

51. Yoshida K, Sato K, Tonogi M, Tanaka Y, Yamane G, Katakura A. Expression of cytokeratin 14 and 19 in process of oral carcinogenesis. Bull Tokyo Dent Coll. 2015;56(2):105-11. https://doi.org/10.2209/tdcpublication.56.105 PMid:26084998

52. Sharief R, Ponnniah I. Expression of cytokeratin 14, cytokeratin 19 and E-Cadherin in ameloblastoma correlates with the cytodifferentiation of enamel organ. J Oral Maxillofac Surg Med Pathol. 2018;30(4):371-9.

53. Gruver AM, Amin MB, Luthringer DJ, Westfall D, Arora K, Farver $\mathrm{CF}$, et al. Selective immunohistochemical markers to distinguish between metastatic high-grade urothelial carcinoma and primary poorly differentiated invasive squamous cell carcinoma of the lung. Arch Pathol Lab Med. 2012;136(11):1339-46. https://doi.org/10.5858/ arpa.2011-0575-OA

PMid:23106579

54. Nakayama $\mathrm{H}$, Mitomi $\mathrm{H}$, Imamhasan $\mathrm{A}$, Uchida $\mathrm{S}$, Tomita $\mathrm{N}$, Kajiyama $\mathrm{Y}$, et al. Stepwise overexpression of p63, p53, and cytokeratin 14 during progression of esophageal squamous intraepithelial neoplasia: Useful immunohistochemical markers for differential diagnosis. Esophagus. 2011;9(1):1-8.

55. Cheung K, Gabrielson E, Werb Z, Ewald A. Collective invasion in breast cancer requires a conserved basal epithelial program. Cell. 2013;155(7):1639-51. https://doi.org/10.1016/j. cell.2013.11.029
PMid:24332913

56. Gao X, Wu J, Cao M, Gao SY, Cen X, Jiang YP, et al. Cytokeratin-14 contributes to collective invasion of salivary adenoid cystic carcinoma. PLoS One. 2017;12(2):e0171341. https://doi.org/10.1371/journal.pone.0171341 PMid:28152077

57. Volkmer J, Sahoo D, Chin R, Ho PL, Tang C, Kurtova AV, et al. Three differentiation states risk-stratify bladder cancer into distinct subtypes. Proc Natl Acad Sci. 2012;109(6):2078-83. https://doi.org/10.1073/pnas.1120605109 PMid:22308455

58. Jangir $H$, Nambirajan $A$, Seth $A$, Sahoo RK, Dinda AK, Nayak $\mathrm{B}$, et al. Prognostic stratification of muscle invasive urothelial carcinomas using limited immunohistochemical panel of Gata3 and cytokeratins 5/6, 14 and 20. Ann Diagn Pathol. 2019;43:151397. https://doi.org/10.1016/j. anndiagpath.2019.08.001 PMid:31494492

59. Cheung K, Ewald A. A collective route to metastasis: Seeding by tumor cell clusters. Science. 2016;352(6282):167-9. https://doi. org/10.1126/science.aaf6546

\section{PMid:27124449}

60. Nagai T, Ishikawa T, Minami $Y$, Nishita M. Tactics of cancer invasion: Solitary and collective invasion. J Biochem. 2020;167(4):347-55. https://doi.org/10.1093/jb/mvaa003 PMid:31926018

61. Alam H, Sehgal L, Kundu S, Dalal S, Vaidya M. Novel function of keratins 5 and 14 in proliferation and differentiation of stratified epithelial cells. Mol Biol Cell. 2011;22(21):4068-78. https://doi. org/10.1091/mbc.E10-08-0703 PMid:21900500

62. Breyer J, Wirtz R, Otto W, Erben P, Kriegmair MC, Stoehr R, et al. In stage pT1 non-muscle-invasive bladder cancer (NMIBC), high KRT20 and low KRT5 mRNA expression identify the luminal subtype and predict recurrence and survival. Virchows Archiv. 2017;470(3):267-74. https://doi.org/10.1007/ s00428-017-2064-8

PMid:28074276 